DOI: $10.25178 /$ nit.2020.2.11

\title{
Личный фонд Саая Бюрбе в Национальном архиве Республики Тыва
}

\author{
Екатерина К. Карелина \\ Новосибирская государственная консерватория им. М. И. Глинки; Сибирский федеральный университет, \\ Российская Федерация \\ Ульяна О. Монгуш \\ Тувинский научный цุентр; Тувинский государственный университет, Российская Федерация
}

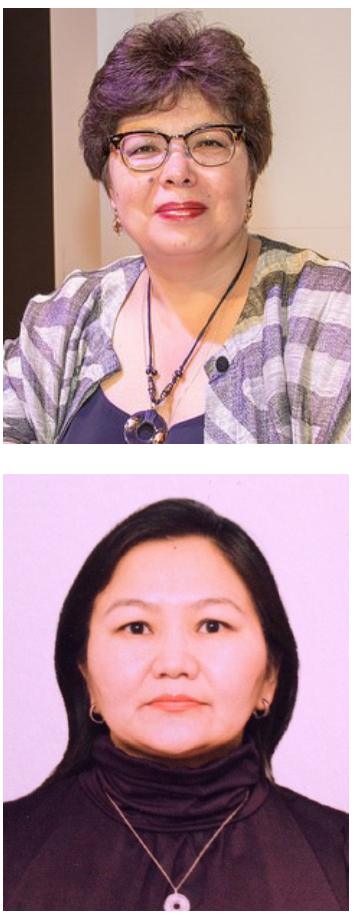

В статье анализируются документы из личного фонда Саая Манмыровича Бюрбе (1924-2012), яркого представителя первого поколения тувинской композиторской школы, чья биография охватывает важнейшие этапы в истории культуры Тувы - досоветский, советский и постсоветский. Документы раскрывают многогранность творческой личности С. М. Бюрбе.

Личный фонд Саая Бюрбе, который сегодня хранится в Национальном архиве (до 07.04.2020 г. - Государственном архиве) Республики Тыва, сложился из документов, предоставленных самим композитором и его детьми. Содержит биографические документы, воспоминания и творческие материалы.

Среди творческих материалов - нотные рукописи произведений разных жанров (симфонические, хоровые, опера «Чечек», песни), афиши концертно-просветительских мероприятий, очерк о тувинских музыкальных инструментах, текст выступления на съезде композиторов Тувы, научно-методическое пособие «Развитие тувинской музыкальной культуры», пособие «Практическая помощь в начальных классах для национальных школ». Личный фонд также содержит публицистику и художественные произведения разных жанров (стихи, баллада, сказка в стихах, басня-сказка, рассказы, историко-документальная повесть, очерк).

Документы личного фонда позволяют не только более полно представить и оценить творческий вклад С. М. Бюрбе в развитие культуры и искусства Тувы, но также содержат материалы, представляющие ценность для исследователей фольклора, истории и традиции тувинцев.

Ключевые слова: архивные документы; личный фонд; Саая Манмырович Бюрбе; тувинская музыка; тувинская литература; композитор; тувинцы; Тува; Государственный архив Республики Тыва; Национальный архив Республики Тыва

\section{Для цитирования:}

Карелина Е. К., Монгуш У. О. Личный фонд Саая Бюрбе в Национальном архиве Республики Тыва // Новые исследования Тувы. 2020, № 2. C. 165-174. DOI: www.doi.org/10.25178/nit.2020.2.11

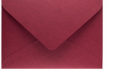

Карелина Екатерина Константиновна - доктор искусствоведения, доцент, доцент кафедры музыкального образования и просвещения Новосибирской государственной консерватории им. М. И. Глинки; профессор кафедры культурологии и искусствоведения Сибирского федерального университета; член Союза композиторов России, заслуженный деятель искусств Республики Тыва. Адрес: 630099, Россия, г. Новосибирск, ул. Советская, д. 31. Тел.: +7 (383) 222-42-16. Эл. адрес: ye karelina@mail.ru ORCID ID 0000-0002-1927-2845

Монгуш Ульяна Очур-ооловна - кандидат филологических наук, ученый секретарь Тувинского научного центра; старший преподаватель кафедры педагогики и методики дошкольного и начального образования Тувинского государственного университета. Адрес: 667000, Россия, г. Кызыл, ул. Интернациональная, д. 117а. Тел.: +7 (999) 124-89-16. Эл. адрес: ochur-ool@mail.ru

ORCID ID 0000-0001-7968-4713

Karelina Ekaterina Konstantinovna, Doctor of Art Studies, Associate Professor, Department of Music Education, M. I. Glinka Novosibirsk State Conservatoire; Professor, Department of Culturology and Art Studies, Siberian Federal University; Member, Russian Union of Composers Union, Honored Worker of Art of the Republic of Tuva. Postal address: 31 Sovetskaia, 630099 Novosibirsk, Russian Federation. Tel.: +7 (383) 222-42-16. E-mail: ye_karelina@mail.ru

Mongush Ul yana Ochur-oolovna, Candidate of Philology, Academic Secretary, Tuvan Research Center; Senior lecturer, Department of Pedagogy and Methodology of preschool and primary education, Tuvan State University. Postal address: 117a Internatsional'naia St., Kyzyl, 667000, Russian Federation. Tel.: +7 (999) 124-89-16. E-mail: ochur-ool@mail.ru 


\title{
Personal collection of Saaya Byurbe at the National Archives of the Republic of Tuva
}

\author{
Ekaterina K. Karelina \\ Glinka Novosibirsk State Conservatoire; Siberian Federal University, Russian Federation, \\ Ul yana O. Mongush \\ Tuvan Research Center; Tuvan State University, Russian Federation
}

\begin{abstract}
The article examines documents from the personal fond of composer Saaya Manmyrovich Byurbe (1924-2012). Saaya Byurbe is a bright figure of the first generation of the Tuvan composers. His biography covers the most important stages in the history of Tuvan culture - pre-Soviet (PRT), Soviet and post-Soviet. The documents reveal the versatility of S. M. Byurbe's creative mind.

Saaya Byurbe`s personal collection, now held at the National Archives (prior to 07.04.2020 known as the State Archives) of the Republic of Tuva, consists of documents donated by the composer himself and provided by his children - biographical documents, memoirs and creative materials.

Among the latter are manuscripts of musical works in different genres (symphonic, choral works, opera "Chechek", and songs), posters from concerts and educational events, an essay on Tuvan musical instruments, the text of Saaya Byurbe's speech at the Congress of Tuva 's composers, a manual titled "Developing musical culture in Tuva", and another one, "Practical assistance in primary national schools". The personal collection also contains essays and literary works in different genres (poems, a ballad, a fairy tale in verse, a fable-cum-fairy tale, short stories, a piece of documentary fiction and a short sketch).

A study of S.M. Byurbe's personal fund has allowed us not only to present and assess his contribution to Tuvan culture in a new light, but also to discover materials of great research value and of interest to researchers of Tuvan folklore, history and tradition.
\end{abstract}

Keywords: archival documents; personal collection; Saaya Manmyrovich Byurbe; Tuvan music; Tuvan literature; composer; Tuvans; Tuva; State Archives of the Republic of Tuva; National Archives of the Republic of Tuva

\section{For citation:}

Karelina E. K. and Mongush U. O. Personal collection of Saaya Byurbe at the National Archives of the Republic of Tuva The New Research of Tuva, 2020; 2: 165-174. (In Russ.). DOI: www.doi.org/10.25178/nit.2020.2.11

\section{Введение}

Роль личных фондов в изучении истории культуры трудно переоценить, особенно когда речь идет о непосредственных участниках и лидерах культурной жизни. Безусловно, в число последних входит Саая Манмырович Бюрбе ${ }^{1}$ (1924-2012), заслуженный работник культуры Тувы и России, представитель старшего поколения тувинских композиторов, соратник А. Б. Чыргал-оола и Р. Д. Кенденбиля. Однако, в отличие от них, имя Саая Бюрбе не увековечено ${ }^{2}$ и редко упоминается в ряду классиков тувинской музыки, а его творчество не стало непременным элементом учебных курсов национально-региональной направленности в учебных заведениях Республики Тыва. На наш взгляд, именно недостаточная изученность творческого наследия Саая Бюрбе в тувинском искусствознании не позволяет дать объективную оценку его личного вклада в развитие культуры Тувы. Имеющиеся документы личного фонда (Ф-743л) из Национального архива Республики Тыва (Государственного архива Республики Тыва, ГА РТ) $)^{3}$ помогают исправить историческую несправедливость по отношению к одному из одарённейших

\footnotetext{
${ }^{1}$ Разночтения в написании фамилии композитора связаны с тем, что в паспорте фамилия зафиксирована как Бюрбю, из-за чего в сокращённом варианте написания имени композитора - С. Бюрбю - его нередко путают с известным в республике писателем Сергеем Пюрбю. Изначально имя композитора - Бюрбе (Бюрбээ, Пюрбе), но при паспортизации он взял в качестве личного родовое имя саая (в то время как, например, его младший брат - кандидат физико-математических наук Хеймер-оол Манмырович Саая - сохранил родовое имя в качестве фамилии). В культурном сообществе Тувы паспортный вариант фамилии композитора (Бюрбю) не прижился, чаще используются варианты Бюрбээ/Бюрбе.

${ }^{2}$ Имя А. Б. Чыргал-оола с 1992 г. носит Кызылский колледж искусств, имя Р. Д. Кенденбиля с 2002 г. присвоено Республиканской школе искусств.

${ }^{3}$ В связи с тем, что переименование архива пришлось на период предпечатной подготовки статьи (7 апреля 2020 г.) далее мы сохраняем в тексте старое название "Государственный архив Республики Тыва" и аббревиатуру "ГА РТ". - ред.

Editors' note: Since the Archives was renamed while editorial work on the article was already under way (April 7, 2020), we have preserved at some places the institution's old name - "State Archives of the Republic of Tuva".
} 
представителей тувинского народа. Предлагаемая статья призвана служить этой цели и задумывалась в связи с 95-летием со дня рождения композитора ${ }^{1}$.

Судьба подарила Саая Бюрбе долгую жизнь (полных 87 лет), в течение которой он пережил эпохальные для развития культуры Тувы исторические события. Годы рождения Саая Бюрбе и молодого тувинского государства почти совпали: неудивительно, что именно эпоха Тувинской Народной Республики (далее - ТНР) сформировала личность будущего композитора. Далее он становится активным участником культурной жизни советской Тувы, продолжает творческую деятельность и в постсоветское время (в сложные 1990-е гг. смог внести личный вклад в сохранение культурного достояния Тувы²).

Благодаря общительной натуре и содействию композитора основные события его жизни и творческой биографии нашли свое отражение в учебной практике курса «Тувинская музыкальная литература», разработанного музыковедом 3. К. Казанцевой ${ }^{3}$ для учащихся музыкальных специальностей Республиканской школы искусств и Кызылского колледжа искусств. С рядом дополнений (полученных лично от композитора) эти материалы вошли в монографию (Карелина, 2009: 239-241), однако, творческая биография С. М. Бюрбе всё же нуждается в уточнениях и расширении фактологического базиса. Как показы-

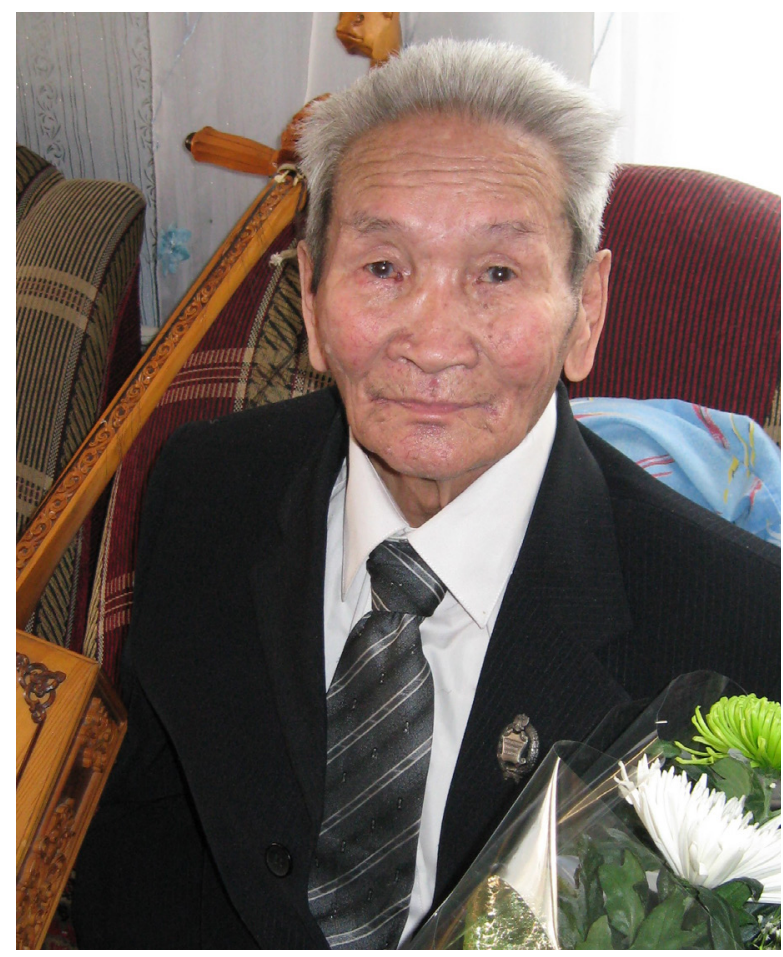

Фото 1. Саая Манмырович Бюрбе в день своего 85-летия, 5 декабря 2009 г., г. Кызыл. Фото Е. К. Карелиной. Photo 1. Saaya Manmyrovich Byurbe on his 85th birthday, December 5, 2009, Kyzyl. Photo by E. K. Karelina. вает наш опыт в работе с личным архивом композитора Х. К. Дамба (Карелина, Монгуш, 2018), подобная работа и дополнение творческой биографии с помощью разного рода документов и, казалось бы, незначительных фактов может значительно углубить представления о личности, мотивах творческой деятельности, помогает выстроить целостную и более полную картину жизненного и творческого пути, вникнуть в концепцию произведений.

Сложность поставленной задачи частично объясняется тем, что среди многих талантливых представителей тувинского народа Саая Бюрбе выделяется редким сочетанием разнообразных дарований ${ }^{4}$ он не только композитор, исполнитель-певец и инструменталист (играл на многих тувинских традиционных инструментах, а также на баяне и фортепиано), музыкант-организатор, но и борец, танцор, а также журналист, писатель и поэт, педагог-просветитель, лектор, методист, наставник творческой молодежи. В связи с этим любой исследователь будет склонен писать его биографию в ракурсе своей профессиональной специализации. Поэтому оптимальным в случае с Саая Бюрбе может стать комплексный подход, позволяющий охватить многогранность творческой личности во всём объеме, что, в итоге, будет способствовать более объективной оценке его роли и места в истории тувинской культуры.

\footnotetext{
${ }^{1}$ Данная юбилейная дата (5 декабря 2019 г.), к сожалению, не нашла отражения в ленте событий культурной жизни Тувы.

${ }^{2}$ Будучи принятым в 1993 г. в члены Союза композиторов России, С. М. Бюрбе руководил объединённым союзом профессиональных и самодеятельных композиторов Республики Тыва в период 1993-1997 гг., организуя пленумы, концерты, творческие встречи авторов со слушателями.

${ }^{3}$ Казанцева 3. К. Саая Манмырович Бюрбе. Лекция по курсу «Тувинская музыкальная литература». Кызыл, 1990-е гг. (рукопись).

${ }^{4}$ Неслучайно на уроках тувинской музыкальной литературы в период своей активной работы с учащимися музыкальных отделений Республиканской школы искусств и Кызылского училища искусств в 1980-2000-х гг. известный педагог Тувы 3. К. Казанцева давала ученикам задание перечислить все таланты Саая Манмыровича. Она первая из педагогов стала включать его творческую биографию в учебный процесс, и при помощи такого необычного задания педагог хотела подчеркнуть уникальность личности С. Бюрбе, которого знала лично. Добавим, что по первому профессиональному образованию С. М. Бюрбе был бухгалтером.
} 


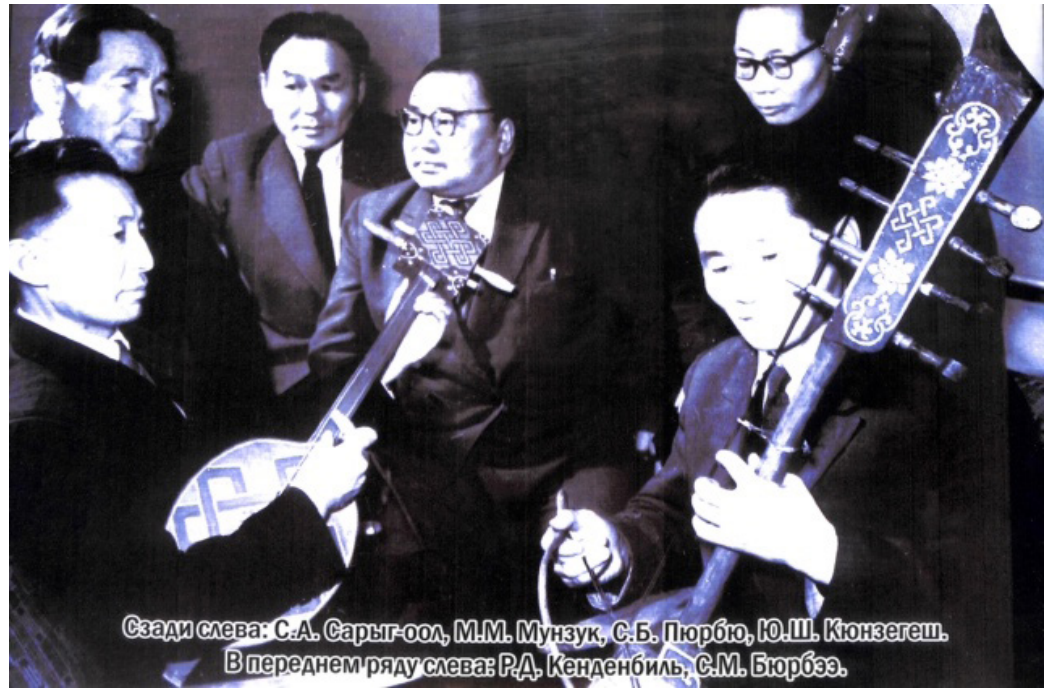

Фото 2. С. М. Бюрбе с деятелями культуры и искусства Тувинской АССР композитором Р. Д. Кенденбилем, артистом М. М. Мунзуком, писателями С. А. Сарыг-оолом, С. Б. Пюрбю, Ю. Ш. Кюнзегешем. Примерно начало 1960-х г2. Из фондов Государственного архива Республики Тыва.

Photo 2. S. M. Byurbe with workers of culture and art of the Tuvan ASSR - composer

R. D. Kendenbil', artist M. Munzuk, writers A. S. Saryg-ool, S. B. Pyurbyu, Yu. Sh. Kyunzegesh, early 1960s (?) (SA RT).
Научная новизна предлагаемой статьи определяется тем, что до настоящего времени материалы личного фонда Саая Бюрбе не становились предметом специального изучения.

\section{Особенности фонда}

Личный фонд Саая Бюрбе (ГА РТ, ф-743л, оп. 1) сформирован из трех частей: в 1-ю вошли дд. 1-33, во 2-ю - дд. 34-58, в 3-ю - дополнение к оп. 1 (включены дд. 1-4). В итоге, фонд содержит 62 единицы и сложился из документов, предоставленных самим композитором (дважды - в 1998 г. и в 2003 г.); после смерти композитора фонд был дополнен его детьми (в 2014 г.).

Музыкально-творческая деятельность С. М. Бюрбе отражена в личном архиве различными документами. Перечислим их и отметим их источниковедческую ценность:

- рукописные материалы (дд. 14, 20) о тувинских музыкальных инструментах (на тув. яз.) и научнометодическое пособие «Развитие тувинской музыкальной культуры» (на тув. яз.) 1999-2000 гг. (д. 57). Они могут представлять интерес для этноинструментоведов, историков музыки и культурологов, как ценные с позиции взгляда носителя традиции ${ }^{1}$ и одновременно композитора академической школы;

- текст выступления на съезде композиторов Тувы (на рус. яз.), помеченный 1957 г. (д. 38), сценарий тематического концерта, посвященного 60-летию образования СССР «Союзу братства - 60, Туве советской - 38» (на тув. яз.) 1981 г. (д. 47), афиши концертно-просветительских мероприятий и пригласительные на юбилейные концерты (дд. 25-30, 58). Эти документы будут интересными для историков музыки и культурологов как документы творческой биографии и эпохи;

- рукопись пособия «Практическая помощь в начальных классах для национальных школ» (на тув. яз.) 1993 г. (д. 54) может быть познавательной для педагогов-практиков, ведь в период 1990-х гг. С. М.Бюрбе работал в Институте развития педагогического образования, заведовал отделом музыкального образования, под его руководством издавались учебно-методические пособия для учителей музыки;

- нотную часть фонда, ценную для музыковедов и музыкантов-практиков, представляют песни разных лет, периода с 1962 по 2000 гг. (д. 39; дополнение к оп. 1, д. 1), клавир оперы «Чечек» 1963-1975 гг. (д. 41), хоровая кантата «Слово о Хемчике» 1993 г. (д. 55) и ряд оркестровых партитур: «Детская сюита» 1962 г. (д. 40), І часть симфонической картины «В лесу» 1973 г. (д. 43), симфоническая поэма № 21975 г. (д. 45), концерт-поэма для виолончели с оркестром 1975 г. (д. 46), симфоническая картина 1984 г. (д. 49 ).

\footnotetext{
${ }^{1}$ Отец Саая Бюрбе был народным мастером-изготовителем тувинских инструментов, а сам Саая Манмырович не только владел игрой на них, но и вел класс фольклорных инструментов на стадии становления отделения тувинских инструментов в Кызылском училище искусств, издал учебное пособие (Бюрбе, 1997). Этномузыковед В. Ю. Сузукей справедливо отмечает: «В настоящее время все ощутимее становится неизбежное численное уменьшение носителей традиционной культуры устно-слухового типа в связи с их естественным уходом из жизни, и по этой причине происходит ослабление влияния и снижение их роли в культуре» (Сузукей, 2017: 8). В этой связи ценность учебного издания С. М. Бюрбе осмысляется по-особому, поскольку он был не только носителем живой традиции тувинского инструментализма, но и квалифицированным педагогом-методистом. ${ }^{2}$ Нам известно о съезде тувинских композиторов 1962 г., исторически засвидетельствованного факта композиторского съезда в Туве ранее 1962 года мы не обнаружили. Данный документ стимулирует поиск иных свидетельств в пользу проведения подобных мероприятий в более ранние годы.
} 


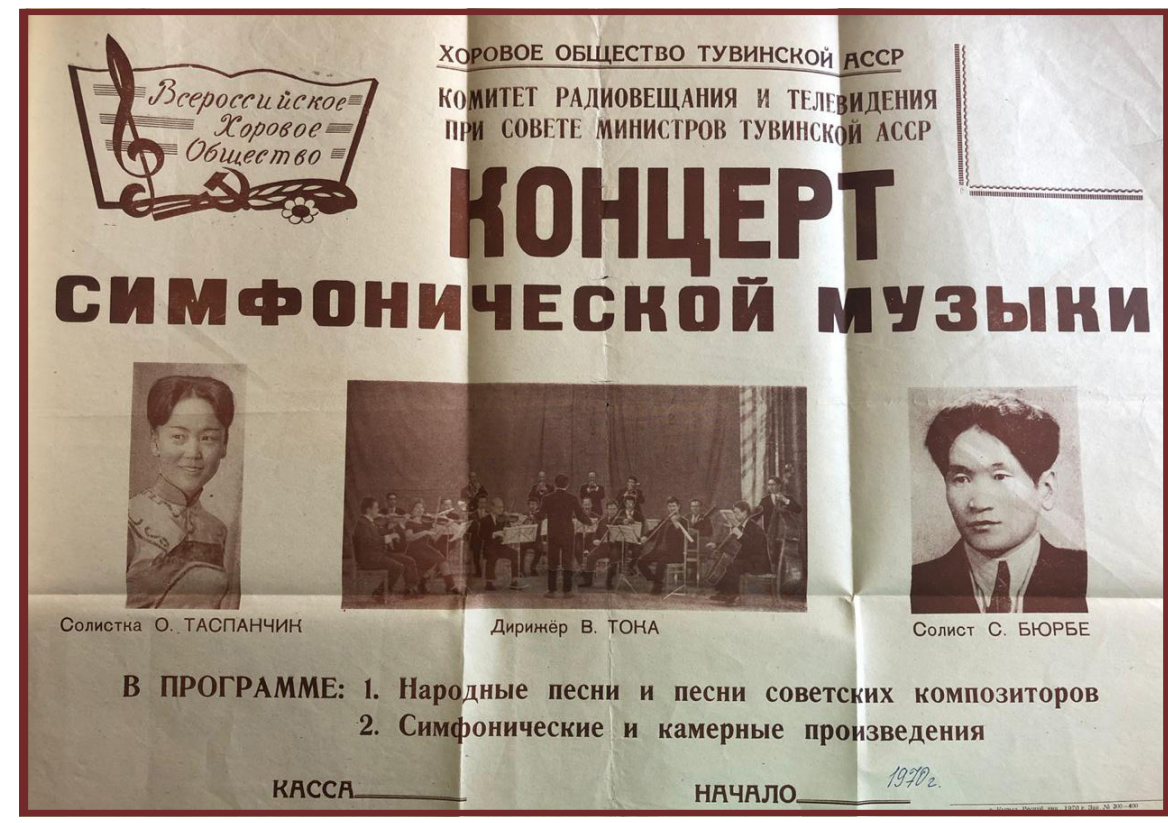

Фото 3. Афиша концерта симфонического оркестра, 1970 г. (ГА РТ, ф-743л., оп. 1, д. 25). Photo 3. Poster of a Symphony orchestra concert, 1970 (SA RT, f. 743l, op. 1, d. 25).
Биографические документы включают автобиографию, датированную 1987 г. (д. 1), воспоминания об отце (дд. 2, 35), о сестре (д. 7), копии удостоверений к юбилейным медалям (дд. 31, 32), афиши мероприятий (дд. 25-29). Среди последних привлекает внимание афиша семейного концерта за 1989 г. (д. 28), на которой полно представлена семья композитора: Саая Манмырович, его супруга Роза Туматовна, их дети Чечек, Сайгын и Айдыс, сестра и брат жены Татьяна Туматовна и Сергей Туматович Балдан, а также зять Хомушку Эзир-оол Эрес-оолович. Семья С. М. Бюрбе являет собой пример крепких семейных связей, не только родственных, но и творческих ${ }^{1}$.

\section{Проблемы исследования музыкального наследия С. М. Бюрбе}

Имеющиеся рукописи позволят внести коррективы в хронологию создания ряда произведений, а также представляют музыковедам возможность анализа ряда малоизвестных и уже забытых сочинений, занимающих определенное место в истории развития академических музыкальных жанров в Туве. Целый ряд произведений из вышеназванных пока не нашли своего полноценного отражения в музыковедческой литературе. Например, хоровая кантата «Слово о Хемчике» исполнялась в Туве в период 1990-х гг., с учетом немногочисленности произведений данного жанра в тувинской музыке она представляет несомненный интерес для исследователей и исполнителей.

Есть вопросы в связи с идентификацией симфонических произведений С. М. Бюрбе, который (как и другие тувинские авторы) нередко менял программные заголовки, порой и жанровое обозначение. Так, симфоническая картина 1973 г. (с указанной 1 частью под названием «В лесу»), с учетом вариативности жанровой атрибутации (особенно свойственной тувинским авторам старшего поколения), может оказаться вариантом одной из поэм С. М. Бюрбе. Симфоническая поэма № 21975 г. - возможно, симфоническая поэма «Рождённая Октябрем». По вышеуказанной причине, симфоническая картина 1984 г. может оказаться симфонической поэмой «Хуреш».

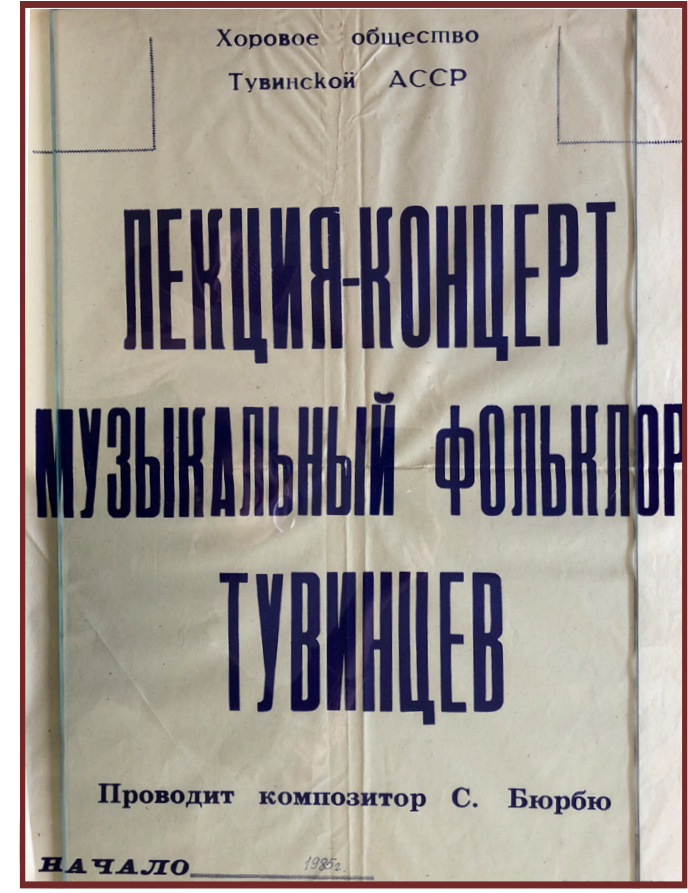

Фото 4. Афиша лекции-концерта, 1985 г. (ГА РТ, ф-743л., on. 1, д. 27).

Photo 4. Poster of a lecture-concert, 1985 (SA RT, f. 743l, op. 1, d. 27).

\footnotetext{
${ }^{1}$ Имя Татьяны Балдан в культуре Тувы тесно связано с историей развития тувинского национального оркестра (Карелина, 2009: 266-269), супруга Роза Туматовна тоже была работником культуры, а их сын Сайгын (как когда-то сам Саая Манмырович) получил хореографическое образование. Свои последние годы, после ухода из жизни супруги, С. М. Бюрбе проживал с дочерью и зятем.
} 
Для уточнений полного списка и хронологии создания произведений потребуется сверка архивных материалов ГА РТ с рукописями композитора, имеющимися в библиотеке симфонического оркестра Тувинской государственной филармонии им. В. М. Халилова, Музыкальном фонде (Музфонде) Тувинского регионального отделения Союза композиторов России, кабинете тувинской музыки Кызылского колледжа искусств им. А. Б. Чыргал-оола, фондах отдела по искусству Национальной библиотеки РТ им. А. С. Пушкина.

Одним из уникальных в тувинской культуре является Концерт-поэма для виолончели с оркестром 1975 г. Саая Бюрбе. В комплексе с его более известным альтовым концертом «Узун-хоюг» ${ }^{1}$ оба этих сочинения до сих пор являются единичными примерами концертных партитур для данных инструментов в тувинской музыке и заслуживают специального внимания ${ }^{2}$.

Рукопись имеющейся в ГА РТ Детской сюиты 1962 г. позволяет внести уточнения. Нам известны две детские сюиты С. М. Бюрбе, партитуры которых хранятся в библиотеке симфонического оркестра Тувгосфилармонии. При этом, партитура 1977 г. озаглавлена автором как Первая сюита, а другая, без номера и года - «Детская сюита», музыка которой базируется на 7 детских фортепианных пьесах автора и по музыкальному тексту совпадает с партитурой, хранящейся в ГА РТ. Следовательно, последнюю из названных следует считать первой, а сюиту 1977 г. (состоящую из 4-х частей) - второй. Добавим, что в детской сюите 1977 г. часть № 3 озаглавлена автором «Утро в лесу» (см. д. 43 из личного фонда Саая Бюрбе в ГА РТ). Сопоставление партитур из оркестровой библиотеки и ГА РТ может помочь в уточнении связей между детскими сюитами и симфоническими поэмами ${ }^{3}$.

Песенное творчество Саая Бюрбе специально не изучалось, хотя, например, его песня «Тувинский соловей» была в свое время чрезвычайно популярной и была включена в программу концерта в зале Кремлёвского Дворца съездов среди сочинений первых тувинских композиторов, исполнявшихся на первой Декаде тувинского искусства в Москве 16 октября 1964 г. Песенная часть творческого наследия С. М. Бюрбе, на наш взгляд, заслуживает специального внимания музыковедов.

В целом, мы убеждены, что более пристальное изучение музыкальных опусов, созданных композитором в период 1960-1990-х гг., сможет существенно расширить профессиональные представления музыкантов о стилистических поисках тувинских авторов в области симфонической, оперной, хоровой

\footnotetext{
${ }^{1}$ Краткая характеристика этого сочинения дана в обзоре Е. К. Карелиной (Карелина, 2009: 373-374).

${ }^{2}$ Особенно в связи с развитием в последние годы виолончельного класса в Республиканской школе искусств и активным участием юных виолончелистов (учащихся школы и студентов колледжа искусств) в концертной практике симфонического оркестра Тувинской филармонии.

${ }^{3}$ Возможно, речь идет об авторском использовании одного материала для разных произведений - явлении в мировой композиторской практике достаточно распространённом.
} 
музыки и в жанре песни. Творчество С. М. Бюрбе пока мало привлекает внимание музыковедов. Одна из причин, по нашему мнению, кроется в стилистических особенностях его музыкальных произведений, что иногда ставят исследователя в тупик. Музыка Саая Бюрбе - явление пограничное, лежащее на пересечении сфер народного и композиторского творчества (новоевропейского типа), поэтому применение традиционных методов академического музыкознания или музыкальной фольклористики не всегда является адекватным. Оптимальным видится подход, гибко сочетающий инструментарий теории и истории музыки с этномузыкологическим анализом материала.

Перспективным может быть рассмотрение творческой деятельности С. М. Бюрбе в системе признаков традиционной профессиональной музыки, предлагаемой авторитетным музыковедом (Галицкая, 2015: 8-11). Полагаем, что подобное «промежуточное» явление между народным и композиторским профессионализмом вполне типично для Тувы и объясняется особым соотношением типов культур, выделяемых в культурологическом исследовании А. В. Костиной (Костина, 2009). В сравнении с другими регионами Российской Федерации, в Туве в силу целого ряда причин академические формы искусства и культурной жизни оказались развиты в гораздо меньшей степени, чем традиционные и современные, что позволило рассматривать культуру Тувы как своеобразный эко-экзо-этнокультурный синтез (Karelina, 2018: 223), коррелирующий с этническими особенностями музыкального мышления, которое в полной мере демонстрирует в своем творчестве Саая Бюрбе.

\section{Литературное наследие С. М. Бюрбе}

Благодаря документам из личного фонда С. М. Бюрбе (ГА РТ, ф-743л, оп. 1) выявляются новые грани творчества талантливого сына тувинской земли.

Литературное наследие композитора характеризуется особенностью языковых нюансов, отраженных в различных стилевых и жанровых разновидностях: периодике, художественной литературе (стихах и прозе), научно-исследовательских статьях. В перечень архивной описи входят поэтические материалы из многочисленных стихотворений, которые Саая Бюрбе начал писать с 1945 г., там же встречаются произведения других жанров: баллада, сказка в стихах, басня-сказка (дд. 11, 12, 23). Оформлены в отдельные архивные дела материалы в прозе - историко-документальная повесть (дд. 10, 53), очерк (д. 51), рассказы (дд. 1, 6-8), воспоминания (дд. 3-5, 54), случаи из жизни (дд. 2, 8), рукописи выступлений и лекций во время гастролей по разным районам (д. 8), на съезде композиторов Тувы (д. 38), а также рукописи заметок, опубликованных в средствах массовой информации (дд. 6, 13, 15-17), письма и научные статьи и сценарии (дд. 9, 14, 24). В основном, личные переживания и творческие задумки автор выражает на родном языке.

Саая Бюрбе в истории культуры Тувы был и остается ярким и авторитетным наставником, продолжателем традиций и носителем языка. Учитывая вышеуказанное, оценку его языковых особенностей следует рассмотреть с точки зрения современных методологических подходов, например, эпистолярного дискурса в свете теории речевой культуры и ее типов. Как отмечает А. В. Курьянович: «Эпистолярий <..> представляет сферу реализации особенностей вербального поведения элитарной языковой личности. Данный тип носителя языка характеризуется особым мышлением, является успешным в коммуникации, соответствует национальным традициям общения, обладает ярким индивидуальным стилем» (Курьянович, 2011: 76).

Чтобы выявить принадлежность к элитарной языковой личности ${ }^{1}$, рассмотрим стилистику С. М. Бюрбе на примере одного его произведения - басни-сказки «Челбиге-курьяк» (Баба-Яга) (д. 23). Автор добавил к обозначению жанровой специфики басни-сказки словосочетание «событие из жизни» или «жизненный случай». Явно, этим он хотел разоблачить конкретного человека, с которым сталкивался в своей жизни. Повсюду в тексте чувствуется основа тувинского речевого эталона - соблюдение сингармонизма гласных, а также аллитерации в начале фраз. Например, aлдар-ады арат-чоннуң сүзүу болуп, хүндүткели хүннээректеп келир орта, адааргааш, бажын ажыр хоп-кошту хоранныг дылы-биле коваңнадып үндүрүпкен - '[Когда слава Золотой царевны] достигла истинного народного признания,

\footnotetext{
${ }^{1}$ Языковая личность - человек, владеющий ресурсами языка и использующий их в качестве средства формирования и выражения мыслей для достижения различных задач в общении и оптимизации коммуникативного процесса в целом (Курьянович, 2015: 199).
} 
уважение засияло, как солнце, [Челбиге курьяк] от зависти ядовитым языком выплеснул, приподнимая голову, много сплетен'; Резюме, ключевая фраза басни - Кускун ышкаш, актыг черге кижилер нүгұлдээрлер ам-даа бистиң аравыста чок деп болбас - букв. 'как ворон, склонный клеветать на людей с чистой совестью, есть такой еще среди нас'.

Арсенал художественного языка С. М. Бюрбе включает много архаизмов: аарыг-аржыкка акташкан - букв. 'соперничать, быть равными с болезнями’ в значении «врачевать»; чымза-чимзе овду ‘таежная трава с лечебными свойствами’; шары кежиниң чартыы хире саазынга хоп-нүгүлдүг өргүүделин aumыn бижээш - букв. 'написав заявление со сплетнями-клеветой на бумаге размером с половины шкуры вола’; этнонимов - Чеди чааның чес мыйыс дег айы - 'седьмая доля нового месяца, похожего на медный рог', Чеди-хаан өг дүндүүнге четкелекте - 'когда звезда Большой Медведицы достигала дымового отверстия юрты’. Отметим изобилие окказиональных фразеологизмов, эпитетов, метафор: ак-мак четпээнде - букв. 'беспрепятственно’ в значении ‘быстро', чүрээ балартап - букв. 'сердце, покрытое тиной’ в значении 'заболеть', уйгу бастырып - букв. 'подавленный сном’ в значении 'подкрадываться, злоупотребляя самым пиком времени спящего’ чоорганыңар аштынган - букв. «одеяло ваше распахнулось» в значении 'дело раскрыто', сооңардан сүргүнчүлүг, мурнуңардан уткуушкуннуг букв. «имеющий позади погоню, спереди встречную церемонию» в значении 'с нечистой историей’, Хамык буруу Челбигеден кайнаар чаштып дезе бээр боор, назынында хөделдирген арын-нүүр чок нүгүлхову аастан үнгеш, агаар эргип, өзүп-хөөреп чорза-чорза, бодунуң-на хилинчектиг борбак бажын дедир эргээн - букв. «вся вина, куда же денется от Челбиге, бессовестные сплетни и клевета, совершенные в ее жизни, вылетая изо рта, вырастая и взбухая на воздухе, возвратились на ее же горемычную голову» в значении 'бумеранг'.

Данные фрагменты лишь одного примера показывают, что система речевого строя С. М. Бюрбе (особый набор художественных средств, тропов, моделей грамматических структур) в письменных источниках остается живым путеводителем и свидетельством его индивидуальных авторских черт.

Особую любовь к художественному слову автор отмечает в дружбе с известным поэтом Тувы Сергеем Пюрбю (д. 37, л. 3). Учитель тувинского языка и литературы общеобразовательной школы № 2 г. Турана М. Н. Ооржак подсчитал, что более тридцати произведений Сергея Пюрбю стали песнями, благодаря мелодиям и музыке Саая Бюрбе (Ооржак, 2014: 7-12).

Добавим, что в качестве литературного критика С.М. Бюрбе написал отзыв на книгу своего земляка, монгун-тайгинского писателя Салчака Молдурга «Сүзүк» (Святыня) (д. 24), также отзыв на стихотворение того же автора «Баапайның ужуралы» (Приключение Баапая) (д. 55).

Особое внимание следует обратить на этнографические материалы, показывающие С. М. Бюрбе как знатока-преемника древних традиций, например, воспоминания о праздновании Шагаа в 1930-х гг. (д. 3). Этнографический материал с предоставлением обрядовых деталей может быть полезным для исследователей фольклора, истории и традиции тувинцев (упоминаются героический эпос «КезерЧингис», знаменитые сказители Монгун-Тайги, обрядовый ритуал сан салыр и народные игры).

Материалы личного фонда С. М. Бюрбе показывают стилевые черты носителя элитарной речевой культуры. В них очевидно постоянное стремление к самообразованию, расширению кругозора; высокий уровень общей культуры; принадлежность к гуманитарной сфере, для кого слово является инструментом практической деятельности: писателям, журналистам, деятелям театра и кино, ученым, политикам, государственным деятелям; привычка и опыт публичных выступлений (Иванчук, 2005:14-15).

Тематика литературных материалов Саая Бюрбе, пропитанная любовью к родной земле и предкам, связана с историческими событиями (революционное восстание $1930-$ х гг. ${ }^{1}$ в м. Бора-Шай, Овюрского района), значимыми личностями, оказавшими роль в построении социалистического общества (в том числе значение воспитания его отцом-вдовцом, трепетное отношение к сестре и брату, наброски составления своей родословной и т. д.). Несмотря на литературные способности С. М. Бюрбе, «писательское перо» выдает его как композитора, музыканта, разносторонне одаренного общественного деятеля культуры и искусства.

${ }^{1}$ Так указано в самой рукописи Бюрбе, точный год установить не удалось. 


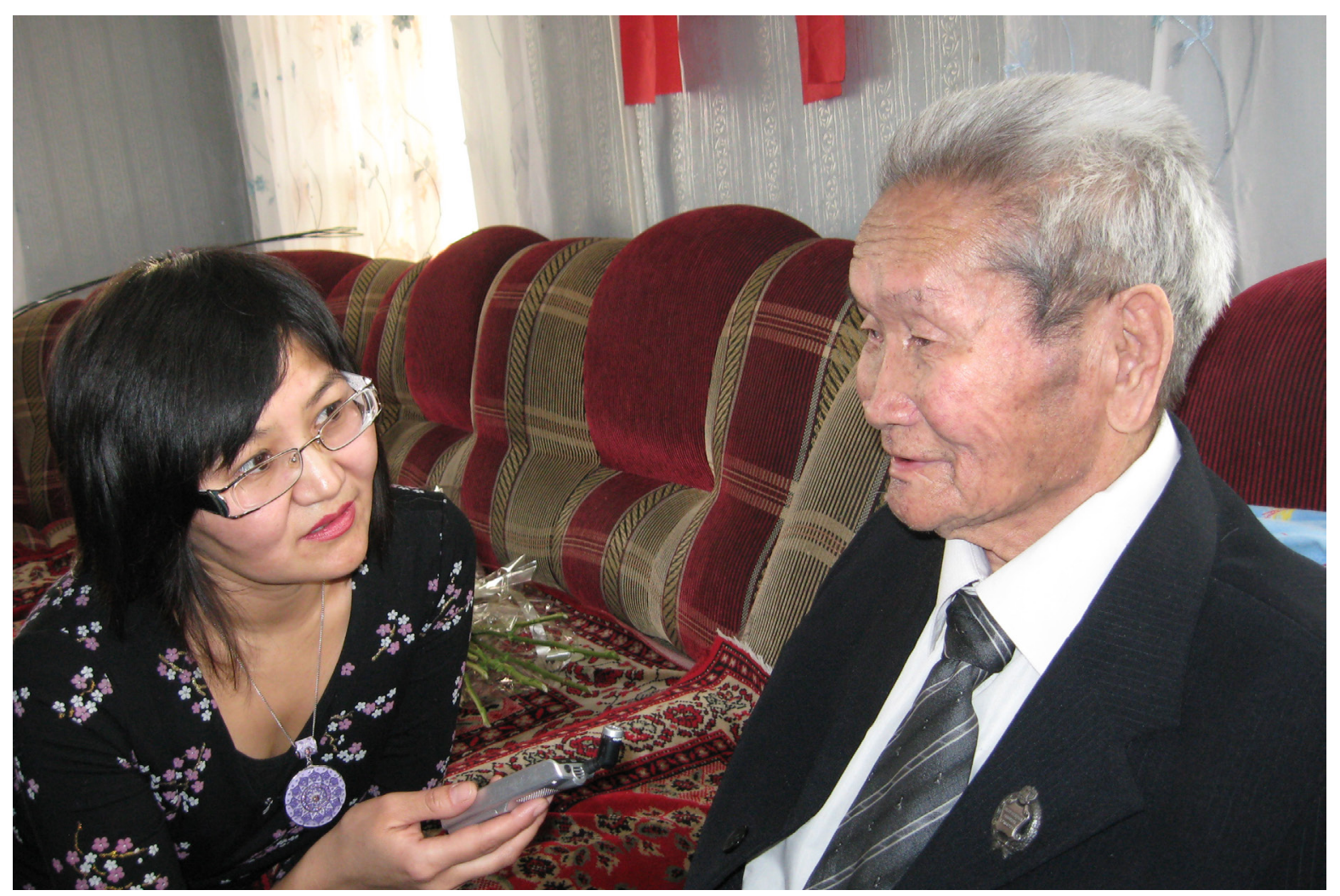

Фото 6. Ульяна Монгуш берет интервью у композитора. 5 декабря 2009 г., г. Кызыл. Фото Е. К. Карелиной. Photo 6. Ul'yana Mongush interviews the composer. December 5, 2009, Kyzyl. Photo by E. K. Karelina.

\section{Заключение}

Вклад Саая Бюрбе в развитие культуры и искусства Тувы еще предстоит оценить в полной мере. Благодаря документам из личного фонда исследователи имеют возможность значительно расширить представления о жизни и творчестве Бюрбе-композитора, а также открыть Бюрбе-писателя (журналиста, критика). Проведенный анализ документов доказывает, что литературное творчество С. М. Бюрбе - важная составляющая его творческого наследия, которое содержит стилевые черты элитарной речевой культуры. Носитель языка и традиций народного искусства, С. М. Бюрбе представляет старшее поколение творческой элиты Тувы. Документы из личного фонда С. М. Бюрбе помогают воссоздавать страницы культурной жизни республики, ряд из них представляет историко-этнографическую ценность.

Саая Манмырович Бюрбе - пример редкого сочетания разнообразных талантов, истинно Народный Мастер, имя которого должно занять почетное место в истории тувинской культуры, а его творческое наследие - звучать с концертной эстрады, публиковаться, исполняться и изучаться в учебных заведениях республики.

Помимо личного фонда С. М. Бюрбе в Государственном архиве Республики Тыва, различного рода документы, связанные с его творчеством, хранятся в фондах Национальной библиотеки Республики Тыва им. А. С. Пушкина, в библиотеке симфонического оркестра им. В. Тока Тувинской государственной филармонии им. В. Халилова, в кабинете тувинской музыки Кызылского колледжа искусств им. А. Б. Чыргал-оола и Музфонде Тувинского регионального отделения Союза композиторов России. В своей совокупности названные фонды позволяют составить достаточно полное представление о творческом наследии Саая Бюрбе, которое достойно специального монографического исследования.

\section{СПИСОК ЛИТЕРАТУРЫ}

Бюрбе, С. М. (1997) Тыва хөгжүм херекселдерин өөредилге черлеринге башкылаарының чыынды программазы: игил, бызаанчы, хомус [Сборник программ для преподавания в образовательных учреждениях игры на тувинских инструментах: игил, бызаанчы, хомус]. Кызыл : б. и. 25 с. (На тув. яз.). 
Галицкая, С. П. (2015) О профессионализме в традиционной музыкальной культуре // Проблемы музыкальной науки. № 4. C. 6-14. DOI: https://doi.org/10.17674/1997-0854.2015.4.006-014

Иванчук, И. В. (2005) Риторический компонент в публичном дискурсе носителей элитарной речевой культуры : автореф. дис. ... д-ра филол. наук. Саратов. 65 с.

Карелина, Е. К. (2009) История тувинской музыки от падения династии Цин и до наших дней : исследование / науч. ред. док. иск. В. Н. Юнусова. М. : Композитор. 552 с.

Karelina, E. K. (2018) The problematic aspects of cultural policy in modern Tuva // Journal of Siberian Federal University. Humanities \& Social Sciences. № 11 (2). P. 218-226. DOI: https://doi.org/10.17516/1997-1370-0217

Карелина, Е. К., Монгуш, У. О. (2018) Личность композитора сквозь призму творческого наследия : к юбилею Хуреш-оола Дамба // Вестник музыкальной науки. № 2 (20). С. 74-84. DOI: https://doi.org/10.24411/2308-10312018-00051

Костина, А. В. (2009) Национальная культура - этническая культура - массовая культура : «Баланс интересов» в современном обществе. М. : Книжный дом «ЛИБРОКОМ». 216 с.

Курьянович, А. В. (2011) Элитарная речевая культура в зеркале отечественной эпистолярной традиции // Вестник Томского государственного педагогического университета. Вып. 3. С. 76-80.

Курьянович, А. В. (2015) Онтологический статус и гносеологические аспекты изучения языковой личности в современной лингвистике // Сибирский филологический журнал. № 4. С. 198-208.

Ооржак, М. Н. (2014) Шүлүк болгаш аялга. Тыва чогаалчыларның ыры апарган шүлүктери [Стих и мелодия. Стихи тувинских писателей, ставшие песнями]. Кызыл ; Красноярск : Офсет. 104 с. (На тув. яз.).

Сузукей В. Ю. (2017) Проблемы научного изучения и практического освоения тувинской музыки (на примере тувинского инструментального искусства) [Электронный ресурс] // Новые исследования Тувы. № 2. URL: https:// nit.tuva.asia/nit/article/view/705 (дата обращения: 15.01.2020). DOI: https://doi.org/10.25178/nit.2017.2.1

Дата поступления: 01.02.2020 г.

\section{REFERENCES}

Byurbe, S. M. (1997) Tyva khogzhum kherekselderin ooredilge cherleringe bashkylaarynyn chyyndy programmazy: igil, byzaanchy, khomus [A collection of programs for teaching Tuvan instruments in educational institutions: igil, byzaanchy, khomus]. Kyzyl, s. n. 25 p. (In Tuv.).

Galitskaya, S. P. (2015) O professionalizme v traditsionnoi muzykal'noi kul'ture [On Professionalism in Traditional Musical Culture]. Problemy Muzykal'noj Nauki / Music Scholarship, no. 4, pp. 6-14 [online] Available at: http://journalpmn. com/index.php/PMN/article/view/238/240 (In Russ.). DOI: https://doi.org/10.17674/1997-0854.2015.4.006-014

Ivanchuk, I. V. (2005) Ritoricheskii component v publichnom diskurse nositelei elitarnoi rechevoi kul'tury [Rhetorical component in the public discourse of elite speech culture and its bearers] : Thesis of Diss.... Doctor of Philology. Saratov. 65 p. (In Russ.).

Karelina, E. K. (2009) Istoriia tuvinskoi muzyki ot padeniia dinastii Tsin i do nashikh dnei [The history of Tuvan music from the fall of the Qing dynasty to the present day]. Moscow, Kompozitor. 552 p. (In Russ.).

Karelina, E. K. (2018) The problematic aspects of cultural policy in modern Tuva. Journal of Siberian Federal University. Humanities \& Social Sciences, no. 11 (2), pp. 218-226. DOI: https://doi.org/10.17516/1997-1370-0217

Karelina, E. K. and Mongush, U. O. (2018) Lichnost' kompozitora skvoz' prizmu tvorcheskogo naslediia : k iubileiu Khuresh-oola Damba [The personality of the composer through the prism of his creative heritage: Essays for the anniversary of Khuresh-ool Damba]. Vestnik muzykal'noi nauki [Bulletin of Music Science], no. 2 (20), pp. 74-84. (In Russ.). DOI: https://doi.org/10.24411/2308-1031-2018-00051

Kostina, A. V. (2009). Natsional'naia kul'tura - etnicheskaia kul'tura - massovaia kul'tura: "Balans interesov" $v$ sovremennom obshchestve [National culture - ethnic culture - mass culture: the "balance of interests" in modern society]. Moscow, Librokom Publ. 216 p. (In Russ.).

Kur'ianovich, A. V. (2011) Elitarnaia rechevaia kul'tura v zerkale otechestvennoi epistoliarnoi traditsii [Elite speech culture in the mirror of the national epistolary tradition]. Vestnik Tomskogo gos. pedagogicheskogo universiteta [Bulletin of Tomsk State Pedagogical University], issue III, pp. 76-80. (In Russ.).

Kur'ianovich, A. V. (2015) Ontologicheskii status i gnoseologicheskie aspekty izucheniia iazykovoi lichnosti v sovremennoi lingvistike [Ontological status and epistemological aspects of the study of language personality in modern linguistics]. Sibirskii filologicheskii zhurnal [Siberian Philological Journal], no 4, pp. 198-208. (In Russ.).

Oorzhak, M. N. (2014) Shuluk bolgash aialga. Tyva chogaalchylarnyn yry apargan shulukteri [Poems and Music. Poems by Tuvan writers that became songs]. Kyzyl, Krasnoyarsk, Ofset. 104 p. (In Tuv.).

Suzukey, V. Yu. (2017) Issues of academic study and practical acquisition of Tuvan music (a case study of Tuvan instrumental music). The New Research of Tuva, no. 2 [online] Available at: https://nit.tuva.asia/nit/article/view/705 (access date: 15.01.2020). (In Russ.). DOI: https://doi.org/10.25178/nit.2017.2.1 